\title{
Statistical and Spatial Analysis of Hurricane-induced Roadway Closures and Power Outages
}

\author{
Mahyar Ghorbanzadeh ${ }^{1}$, Mohammadreza Koloushani ${ }^{1}$, Mehmet Baran Ulak ${ }^{2}$, \\ Eren Erman Ozguven ${ }^{1, *(1)}$ and Reza Arghandeh Jouneghani ${ }^{3}$ (i)
}

1 Department of Civil and Environmental Engineering, Florida Agricultural and Mechanical University-Florida State University College of Engineering, Florida State University, Tallahassee, FL 32310, USA; mg17x@my.fsu.edu (M.G.); mk18h@my.fsu.edu (M.K.)

2 Department of Civil Engineering, College of Engineering and Applied Sciences, Stony Brook University, Stony Brook, NY 11794, USA; mehmet.ulak@stonybrook.edu

3 Department of Computing, Mathematics, and Physics, Faculty of Engineering and Science, Western Norway University of Applied Sciences, 5020 Bergen, Norway; reza.arghandeh@hvl.no

* Correspondence: eozguven@fsu.edu; Tel.: +1-850-410-6146

Received: 4 February 2020; Accepted: 28 February 2020; Published: 2 March 2020

\begin{abstract}
Hurricanes lead to substantial infrastructure system damages, such as roadway closures and power outages, in the US annually, especially in states like Florida. As such, this paper aimed to assess the impacts of Hurricane Hermine (2016) and Hurricane Michael (2018) on the City of Tallahassee, the capital of Florida, via exploratory spatial and statistical analyses on power outages and roadway closures. First, a geographical information systems (GIS)-based spatial analysis was conducted to explore the power outages and roadway closure patterns in the city including kernel density estimation (KDE) and density ratio difference (DRD) methods. In order to provide a more detailed assessment on which population segments were more affected, a second step included a statistical analysis to identify the relationships between demographic- and socioeconomic-related variables and the magnitude of power outages and roadway closures caused by these hurricanes. The results indicate that the high-risk locations for roadway closures showed different patterns, whereas power outages seemed to have similar spatial patterns for the hurricanes. The findings of this study can provide useful insights and information for city officials to identify the most vulnerable regions which are under the risk of disruption. This can lead to better infrastructure plans and policies.
\end{abstract}

Keywords: hurricane impact assessment; roadway closures; power outages; density ratio difference

\section{Introduction}

The United States is among the five countries hit the hardest by natural disasters over the last decade [1]. According to the Federal Emergency Management Agency (FEMA), there have been 3728 nationally declared disasters between 1953 and 2018 in the US, including fires (1054), severe storms (923), floods (786), hurricanes (341), and tornadoes (164) [2]. In 2017 and 2018 only, these disasters led to more than 225 billion dollars of economic burden [3,4]. As such, FEMA suggests that, without considering efficient plans, these disasters will have more long-term impacts on communities as well as the economy [2]. Among these hazards, hurricanes, such as the Hurricane Hermine (2016), Hurricane Irma (2017), and Hurricane Michael (2018), have caused substantial infrastructure system damages, such as roadway closures and power outages, in the US, especially in the State of Florida $[5,6]$.

The State of Florida has been exposed to 39 hurricanes, 22 severe storms, and 13 flooding cases since 1953 [2]. Accordingly, Florida ranks first for the number of houses at risk due to the occurrence of these storms and hurricanes, especially because of its long coastline with approximately 2.5 million homes 
along it and the highest total reconstruction cost with nearly $\$ 490$ billion [7]. These hazards disrupt the roadway networks (e.g., roadway and bridge closures) and reduce the efficiency of transportation networks $[4,5]$. For example, Hurricane Irene caused $\$ 65$ million damage to the Vermont transportation network in 2011 [8]. Also, in 1992, Hurricane Andrew caused 1.4 million Florida customers (44\%) to lose power [9]. Recently, Hurricane Michael (2018) left approximately $97 \%$ of electric utility customers without electricity in the City of Tallahassee, the capital of Florida. Two years prior to Hurricane Michael, approximately $80 \%$ of Tallahassee's electrical system was affected by Hurricane Hermine which represents 100,000 customers in the city [10-12]. Furthermore, Hermine caused a substantial amount of roadway closures due to the presence of fallen trees in a one-week window in the City of Tallahassee [5,13].

In the literature, there are several studies that have investigated the consequences of hurricanes on a city's infrastructure systems [14-19]. For example, Davidson et al. [20] investigated the performance of power systems during five hurricanes in North and South Carolina. They examined the relationship between hurricane disruptions and environmental factors such as rainfall, land cover, and maximum wind speed. Demiroluk and Ozbay [21] developed spatial and statistical models to predict the downed trees during two hurricanes in New Jersey. Their results showed that roadway density and maximum wind speed were the most effective variables regarding downed trees probability. There are also several studies that developed statistical models to predict the number of power outages due to the fact of extreme weather events such as hurricanes [22,23]. For example, Reed [24] developed a linear regression model in order to predict power outages due to the fact of windstorms in Seattle. In a similar study, negative binomial regression-based approaches were used to predict hurricane-related outages in North and South Carolina [25]. Eskandarpour and Khodaei [26], on the other hand, applied logistic regression to predict power grid outages in response to an imminent hurricane. Similarly, Han et al. [27] developed a regression model, namely, the generalized additive model (GAM), to estimate power outages during an approaching hurricane. Also, Guikema et al. [28] developed a spatially generalized model to predict hurricane-induced power outages; however, this model has some limitations such as considering maximum $3 \mathrm{~s}$ wind gust. This model was used for Hurricane Sandy. As hurricanes are rare events, none of these studies were able to compare multiple hurricanes with a focus on both power grid and roadway networks together. Many of these studies also did not have real-life power outages and roadway closures to test their models on.

Recently, Ulak et al. [5] investigated the effects of Hurricane Hermine on Tallahassee in terms of power outages using spatial and statistical models. The findings showed that the areas with more senior populations $(65+)$ were highly affected with respect to infrastructure failures. Also, higher-income families were affected less in comparison to other groups, and there was an inverse relationship between power outages and family income. In a similar study, Kocatepe et al. [29] proposed a metric, namely, the Accessibility Decrease Index (ADI) to determine the areas with reduced accessibility to emergency facilities due to the presence of roadway closures before and after Hurricane Hermine in Tallahassee. Also, they conducted a convolutional neural network $(\mathrm{CNN})$ approach to predict the probability of future hurricane-induced roadway closures. In another study, Sultan and Hilton [30] conducted a spatial analysis via GIS techniques to investigate the power outages due to the fact of different events such as tree falling on power lines and weather conditions.

Based on the research gap identified in the literature, this paper proposes the use of GIS in order to identify those locations likely to have high power outages and roadway closure risks with a focus on the City of Tallahassee. A key goal is to produce visual confirmation of event clusters on maps. To the authors' knowledge, there has not been any previous research done specifically focusing on the spatial patterns of power outages and roadway closures involving real-life hurricane data. With this motivation, this exploratory study focuses on identifying and analyzing the locations that pose a high risk of outages and closures for different locations in the city using GIS-based spatial methods, including kernel density estimation (KDE) and density ratio difference (DRD) methods. Observing the need to delve into hurricanes' impact on communities, a multiple linear regression model was 
also developed in order to see which population segments were affected more as a result of the hurricane-induced power outages and roadway closures. This is the key contribution of the paper, which is an important first step towards understanding these dynamics.

The objectives of this paper were: (a) to study roadway closures and power outages in the City of Tallahassee via a comparative assessment of Hurricane Hermine's (2016) and Michael's (2018) impact on these infrastructure networks; (b) to present a GIS-based spatial analysis through the development of the DRD metric which enables a spatial comparison of both hurricane impacts on different sections of the city; and (c) to observe the spatial differences on the impact of hurricanes, a more detailed statistical analysis was conducted through a multiple linear regression model by incorporating factors on socioeconomics and demographics. This analysis can provide more detailed information on which population segments are affected more from power outages and roadway closures. Note also that, real-life power outage and roadway closure data are usually not available due to the lack of interest from private power companies. However, the City of Tallahassee owns its utility services and was willing to share the data under an agreement with the university. The following sections will describe the proposed methodology and results in detail.

\section{Methodology}

This study consisted of three distinct steps to assess and explore the impact of Hurricane Hermine and Hurricane Michael on the City of Tallahassee: spatial and statistical analyses of power outages and roadway closures. The first step included the collection of the data for power outages and roadway closures from the City of Tallahassee. The second step spatial analysis included: (a) data collection for the infrastructure network components, (b) utilizing a series of spatial analytic methods to explore the power outages and roadway closures patterns, including the KDE method to identify the most affected areas due to the fact of Hurricane Hermine and Hurricane Michael, and (c) the DRD in order to understand how the effects of Hermine and Michael are different for the city and assess the differences in locations where power failures and roadway closures were experienced. Following the spatial analysis, a statistical analysis was conducted to comprehend the complexity of power outages and roadway closures in both hurricanes. In this final step, a multiple linear regression (MLR) model was developed to assess the association between hurricane-induced roadway closures and power outages (dependent variables) and demographics-, socioeconomics-, and transportation-related variables (explanatory variables) for both hurricanes. It is important to note that roadway closure in this paper is defined as follows: At least one lane was closed due to the fact of a hurricane. All the above mentioned steps are explained in detail in the following sections.

\subsection{Study Area and Data Description}

The City of Tallahassee, the capital of Florida, was selected for the proposed case study in this paper. According to the 2017 Census estimates, the population of Tallahassee is more than 190,000, and it is the largest city in the Florida Panhandle region [31]. Tallahassee is also home to several universities including Florida State University and Florida Agricultural and Mechanical University which are located around the city center toward the east. The study area is shown in Figure 1. Tallahassee was hit by three major hurricanes since 2016. These events, namely, Hurricane Hermine (September 2016), Hurricane Irma (September 2017), and Hurricane Michael (October 2018) [1,26,27] were among the most significant ones to ever hit the United States. As a result of these extreme events, a substantial amount of roadway closures and power outages was reported due to the downed trees and power lines in the whole city $[1,11]$. Note that, although Hurricane Irma was one of the most powerful hurricanes in history, it did not hit Tallahassee directly. The most substantial damages to the power and roadway network infrastructure in Tallahassee were due to hurricanes Hermine and Michael [32-34]. Figure 2 shows the radar images and paths of these hurricanes over Tallahassee and as observed, the direction of these hurricanes were different $[35,36]$. It should be noted that DBZ in Figure 2 stands for decibels 
of $z$ in which the higher values of DBZ show that the returned power to radar was large, and small values represent less returned energy.

This paper aimed to identify the impacts of Hurricane Hermine and Hurricane Michael on Tallahassee with a specific focus on roadway closures and power outages. As such, different datasets were used including socioeconomic, demographic, power, and roadway networks. Datasets related to the roadway network were obtained from Florida Department of Transportation and those related to power networks were provided by the City of Tallahassee. Furthermore, the roadway closures and power outages data were provided by the City of Tallahassee, through a mobile app called DigiTally (developed by City of Tallahassee, Tallahassee, USA) [37]. DigiTally provides a platform for the residents that can directly connect with the City of Tallahassee. Through this app, residents can report an outage or request a service. Moreover, the data that were related to the demographic and socioeconomic are based on 2013-2017 American Community Survey (ACS) Census estimates [31]. In addition, different emergency facilities, such as "Fire Station", "Hospital", and "Health Center", were considered as part of the case study conducted in this paper [38].

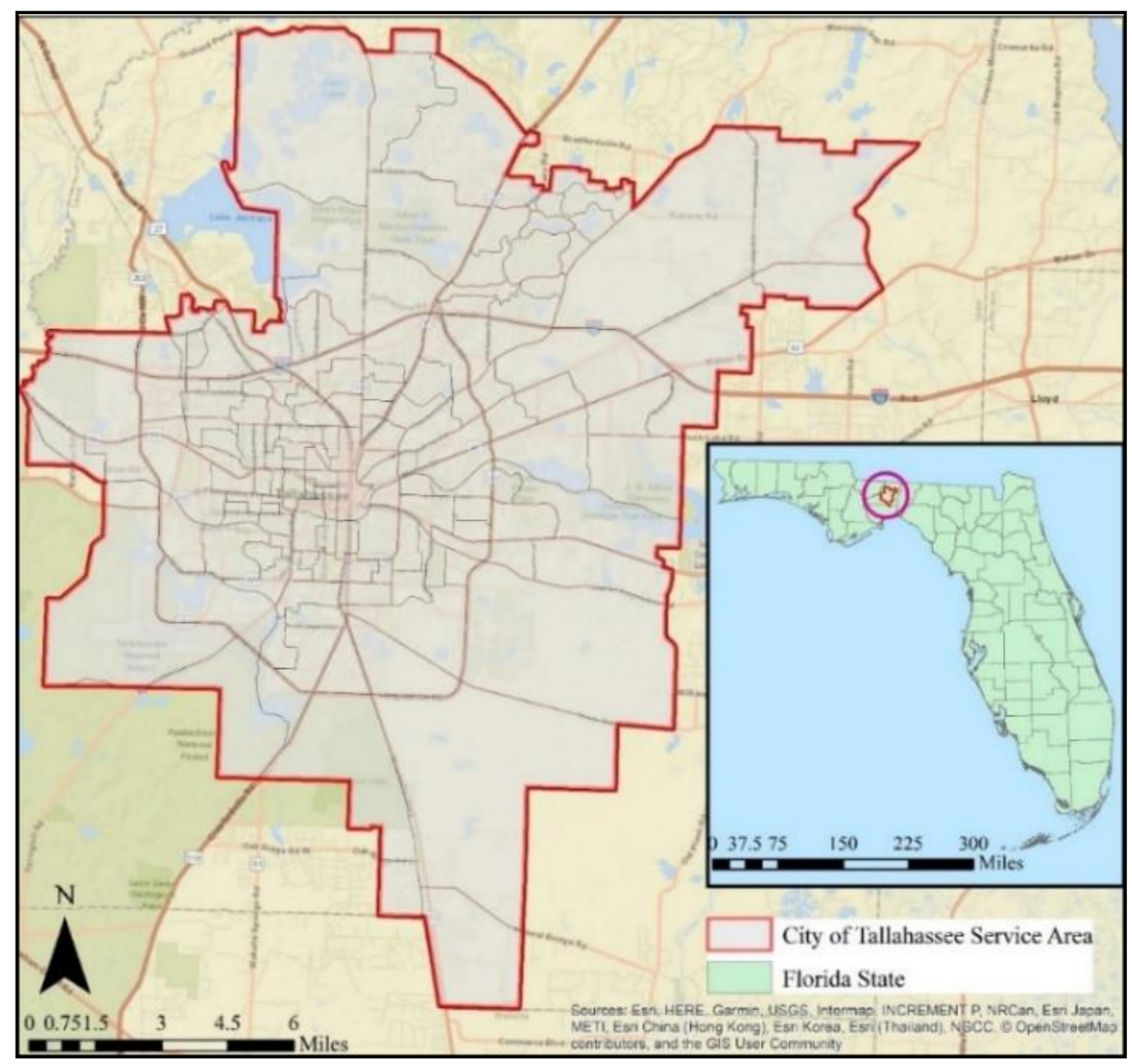

Figure 1. Study area. 


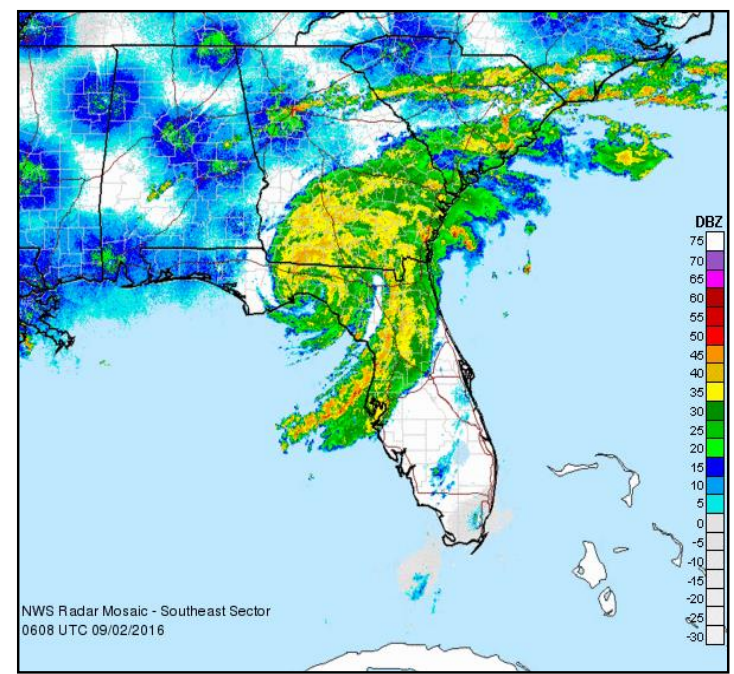

(a)

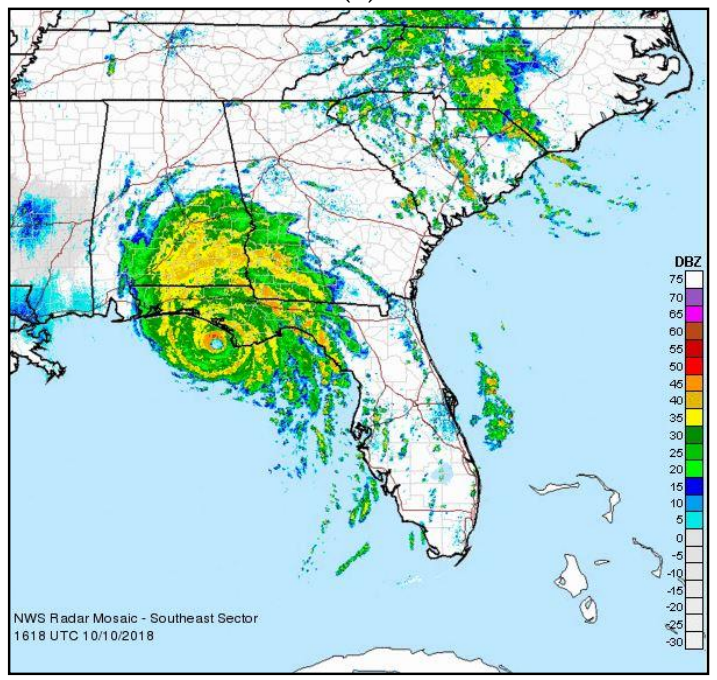

(b)

Figure 2. (a) Hurricane Hermine's [35] (b) and Hurricane Michael's [36] paths over Tallahassee, FL.

\subsection{Spatial Analysis}

\subsubsection{Hurricane-induced Roadway Closures and Power Outages Assessment}

Roadway and power networks are considered multi-layer infrastructure networks, and they are interdependent. For instance, downed trees might cause both roadway closures and power outages. In other words, they increase the outage restoration time by creating difficulties for utility crews to access the disrupted power lines [16]. Thus, assessing the efficiency of these networks should be conducted through a multi-network framework which considers both networks. Figure $3 a, b$ show the power and roadway networks in the City of Tallahassee, respectively. In addition, Figure $3 \mathrm{c}$ displays the emergency facilities spatially, whereas Figure $3 \mathrm{~d}$, f shows the spatial distribution for total population and two vulnerable population segments, young and senior populations, in Tallahassee. In the next step, the roadway closure and power outage density maps were created using the KDE approach and ArcGIS software for both hurricanes Hermine and Michael [5]. Note that in order to apply the KDE analysis, it was necessary to choose a bandwidth. According to the literature, bandwidths with a range of $50 \mathrm{~m}$ to $300 \mathrm{~m}$ are suggested for an urban network [31,32]. On the other hand, bandwidths around $1000 \mathrm{~m}$ are considered as suitable in rural areas [39-41]. Also, there are different types of kernel functions such as normal and uniform. However, bandwidth selection has a significant effect on 
density estimation in comparison to the effect of kernel function [42]. As such, a bandwidth of $200 \mathrm{~m}$ was selected for the study area. This methodology was utilized to investigate the most vulnerable areas to hurricanes in terms of roadway closures and power outages in the City of Tallahassee.

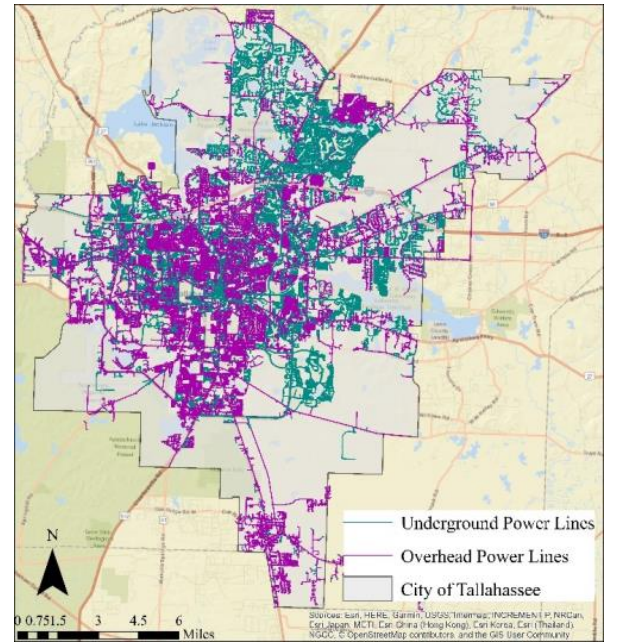

(a)

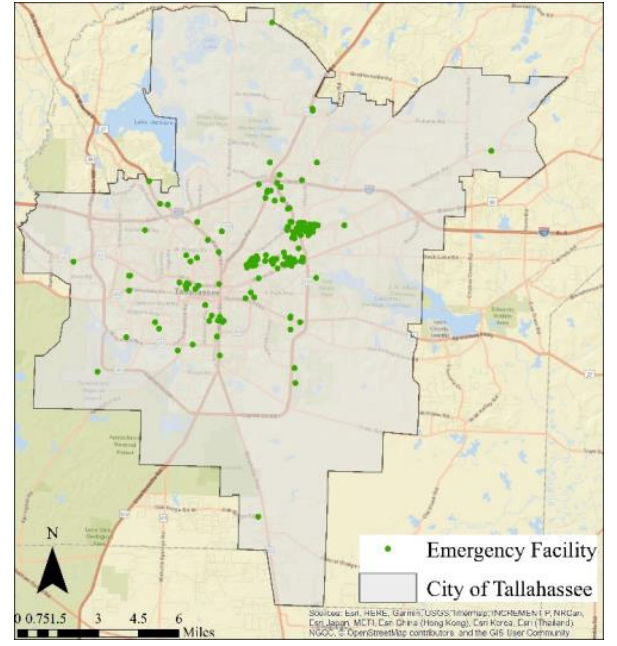

(c)

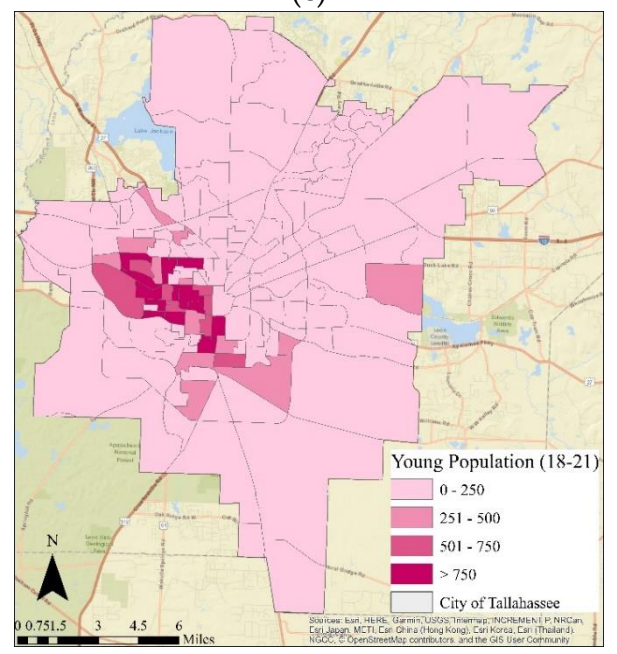

(e)

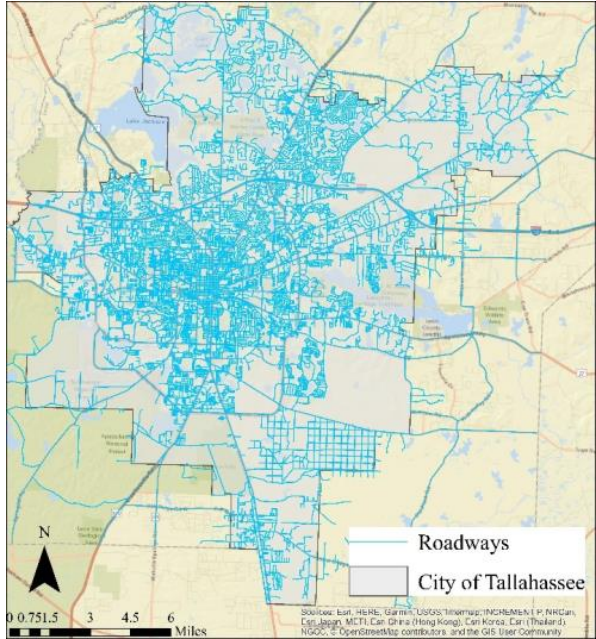

(b)

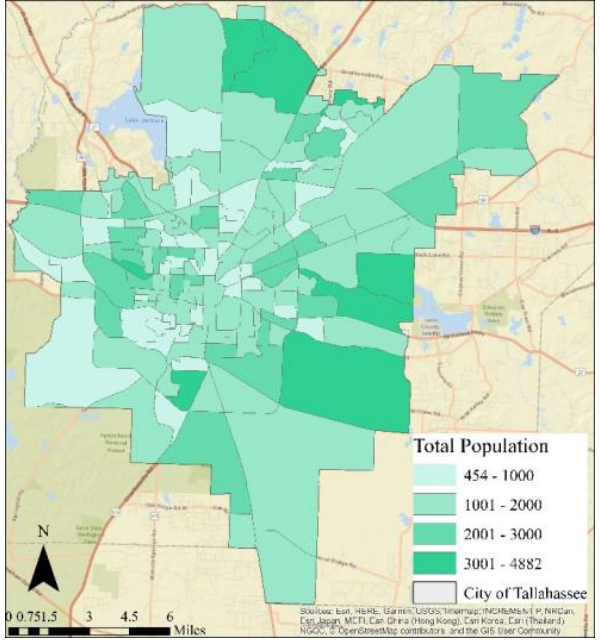

(d)

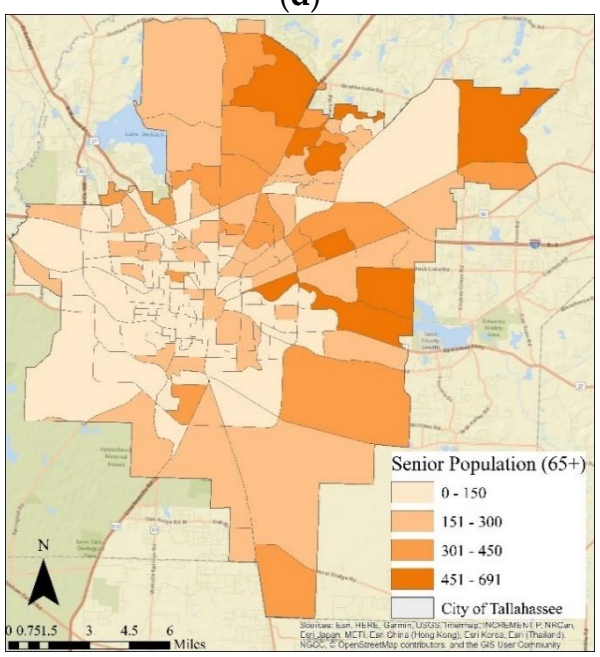

(f)

Figure 3. Power network (a); roadway network (b); spatial distribution of facilities (c); total population (d); young population (18-21) (e); senior population (65+) (f). 
2.2.2. Power Outage and Roadway Closure Density Ratio Differences between Hurricane Hermine and Michael

In order to understand the spatial patterns of the hurricanes' impacts on the city in terms of power outages and roadway closures, a comparative difference density analysis was used through the DRD parameter which was first developed in Reference [40]. The DRD parameter evaluates the difference between the normalized roadway closures and power outages density ratios for Hurricane Hermine and Michael, respectively. The DRD is a useful index to identify and investigate hotspots. For example, based on the calculation of normalized roadway closure densities, roadway closures density maps of Hurricane Michael were subtracted from the roadway closures density maps of Hurricane Hermine. The same idea was used for power outage densities with a focus on both hurricanes. Therefore, the DRD index reveals the relatively different locations on the area which provides even more explicit visual results in terms of geo-spatial differences between two different hurricanes. The formula of the DRD metric is shown as follows (Equation (1)):

$$
D R D_{i j}=\frac{D_{i}}{\max \left(D_{i}\right)}-\frac{D_{j}}{\max \left(D_{j}\right)}
$$

where $D R D_{i j}$ is the "density ratio difference" between the compared maps $\mathrm{i}$ and $\mathrm{j}$, whereas $D_{i}$ and $D_{j}$ are the density values of the corresponding pixels, and $\max \left(D_{i}\right)$ and $\max \left(D_{j}\right)$ are the maximum pixel density values of the compared maps, respectively. Figure $6 a, b$ display the density ratio differences between Michael and Hermine in terms of power outages and roadway closures, respectively. The results of the spatial analysis are provided in the Results and Discussions section.

\subsection{Statistical Analysis}

As previously stated, multiple linear regression models, one of the most common regression techniques, were developed to investigate the impacts of Hurricane Hermine and Michael on the City of Tallahassee and to identify the association between several socioeconomics-, demographics-, and transportation-related variables and power outages and roadway closures induced by these hurricanes. Equation (2) shows the general form of a multiple linear regression model:

$$
y=\beta_{0}+\sum_{i=1}^{n} \beta_{i} x_{i}+\varepsilon_{i}
$$

where $\beta_{0}$ is the intercept term, $x_{i}, i=1,2, \ldots, n$ are the independent variables, $\beta_{i}$ are the regression coefficients, and $y$ is the response variable. Table 1 lists the independent variables utilized in the statistical model along with their definitions. In the current study, four different scenarios were defined: (a) Hurricane Hermine-induced power outages, (b) Hurricane Michael-induced power outages, (c) Hurricane Hermine-induced roadway closures, and (d) Hurricane Michael-induced roadway closures. In the first step of the statistical analysis, the Pearson correlation coefficients between independent variables were obtained. Figure 4 shows the correlations between these variables. It should be noted that the dependent variables of the models are the total number of segments in the city network which experienced power outages and roadway closures due to Hurricane Hermine and Hurricane Michael. A segment here is defined as the power line for the power network, and the roadway link for the transportation network. Finally, the potential models were tested based on the backward stepwise method in order to obtain the final model along with the corresponding variables for each scenario. The findings of statistics-based analyses are summarized in Tables 2-5 for hurricane-induced power outages and roadway closures. The results of the regression models are provided in the Results and Discussions section. 
Table 1. Definitions of independent variables.

\begin{tabular}{|c|c|}
\hline Variables & Definition \\
\hline Land Area $\left(\mathrm{km}^{2}\right)$ & Census land area $\left(\mathrm{km}^{2}\right)$ \\
\hline Normalized Population & Normalized total population density \\
\hline Normalized Households & Normalized total number of households' density \\
\hline Average Household Size & Average household size \\
\hline White (\%) & Percentage of white population \\
\hline African American (\%) & Percentage of black or African American population \\
\hline Young (18-21) (\%) & Percentage of $18-21$ years population \\
\hline Aging $(65+)(\%)$ & Percentage of 65 years and older population \\
\hline Below Poverty (\%) & Percentage of people living below poverty level \\
\hline College Degree (\%) & Percentage of people with at least college degree \\
\hline Zero Vehicle Ownership (\%) & Percentage of people with no vehicle ownership \\
\hline Two or More Vehicles Ownership (\%) & Percentage of people with 2 or more vehicles ownership \\
\hline Use of Car for Transportation (\%) & Percentage of people relying on private cars for transportation \\
\hline Transportation Mode: Walk (\%) & Percentage of people using walk for travel purposes \\
\hline Built After $2014(\%)$ & Percentage of housing units built 2014 or later \\
\hline Disability $(\%)$ & Percentage of people (20-64 Years) with a disability \\
\hline Total Length of Underground Power Lines & Total length of underground power lines, $\mathrm{m}$ (divided by 10,000 ) \\
\hline Total Length of Overhead Power Lines & Total length of overhead power lines, $\mathrm{m}$ (divided by 10,000 ) \\
\hline Emergency Facility Area & Total number of segments within an emergency facility area \\
\hline
\end{tabular}

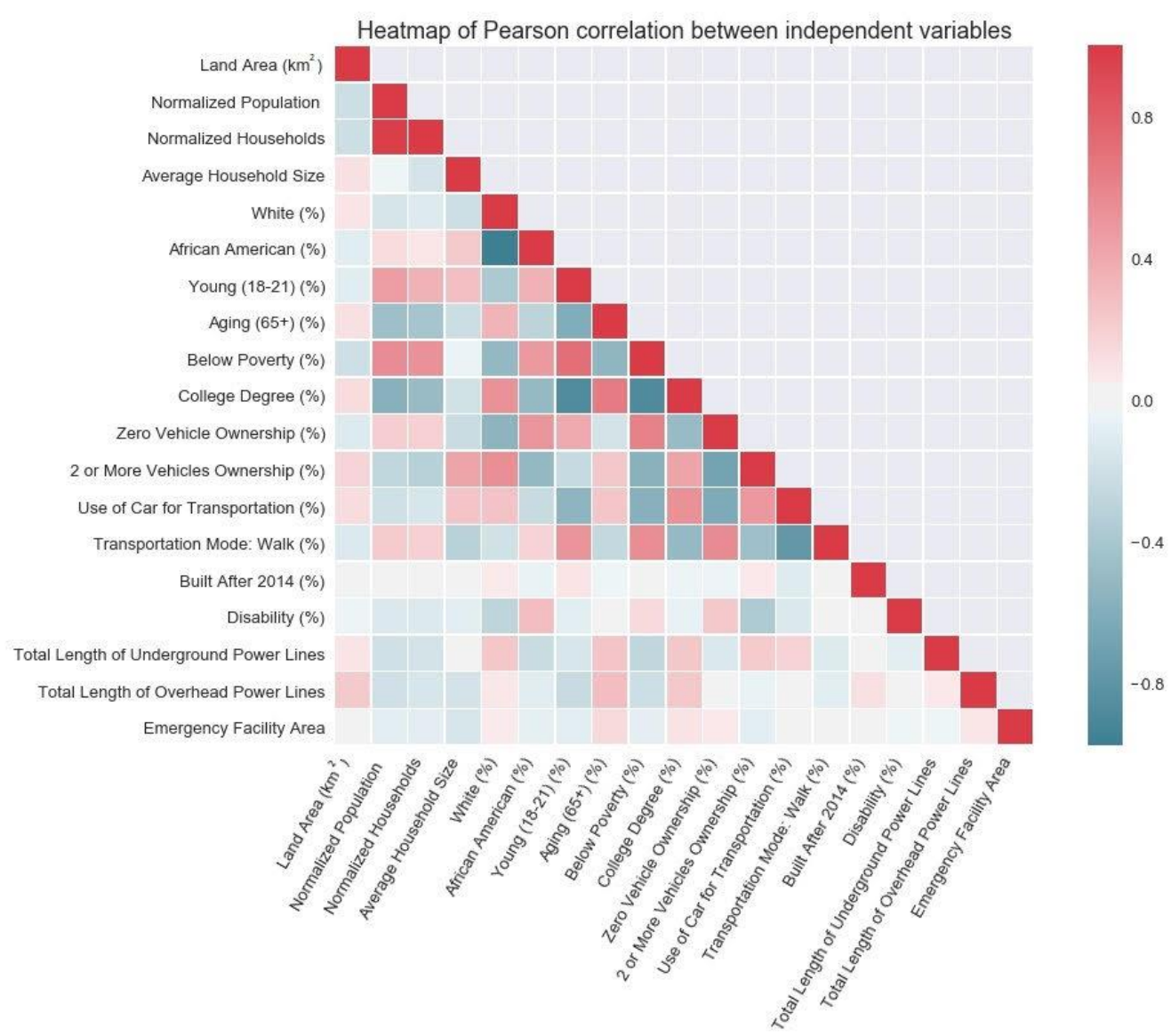

Figure 4. Correlation matrix of independent variables. 


\section{Results and Discussions}

\subsection{Spatial Analysis Results}

\subsubsection{Hurricane-induced Roadway Closures and Power Outages Assessment}

As discussed in the previous sections, a GIS-based spatial analysis was conducted in this study to identify the most affected areas in the City of Tallahassee due to the fact of Hurricane Hermine and Michael with a focus on roadway closures and power outages. Figure 5 illustrates these power outages and roadway closures density maps of the city due to Hurricane Hermine and Michael. The most affected areas due to these hurricanes and power outages and roadway closures locations were identified in order to understand if customers affected by outages and closures were spatially clustered at particular regions or if they were dispersed. Figure $5 a, b$ show the power outage patterns of Hurricane Hermine and Michael, respectively. In these figures, the higher the value of density, the higher the number of power outages caused by both hurricanes in those areas which is shown by the red color. As seen, the highest value of density in Hurricane Michael-induced power outages was greater than the corresponding value in Hurricane Hermine. These figures reveal that the power outages approximately had the same density pattern for both hurricanes Hermine and Michael and almost all sections of the city were affected by these hurricanes. More specifically, the highest power outage densities were observed in the city center so that residents who were living around the city center experienced the highest number of power outages. Similarly, Figure 5c,d reveal the roadway closures patterns in the city due to the fact of Hurricane Hermine and Michael, respectively. The regions with a higher number of roadway closures are shown by the red color. In contrast to power outages, the highest value of density in Hurricane Hermine-induced roadway closure was greater than the corresponding value in Michael. These figures demonstrate that several areas in the city were affected in Hurricane Hermine and Michael; however, it discloses a different pattern for both hurricanes. The highest closure density in Hermine was observed around the city center and downtown Tallahassee. Different to Hermine, the city center and downtown roadways were not affected that much by Hurricane Michael. Two major arterials (namely, Thomasville Rd. and Monroe St.) that lead to Interstate 10 (I-10) in the Northeast and Northwest of Tallahassee had the highest roadway closure densities because of Hurricane Michael. These roadways play important roles in providing transportation accessibility for the residents of the city to the interstate highway and critical facilities such as hospitals. Their closures can cause serious challenges in terms of accessibility for the people and could lead to a reduction in the efficiency of the whole roadway network. The findings also reveal that the areas in the southeastern part of the city were affected less by both hurricanes.

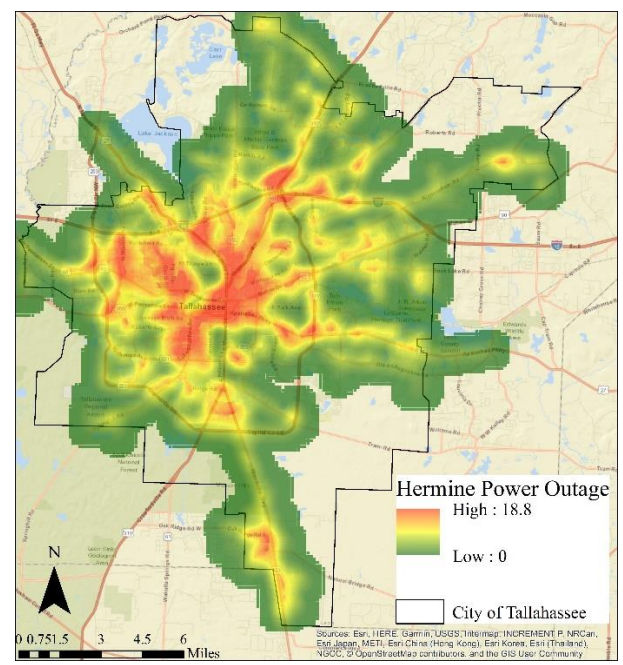

(a)

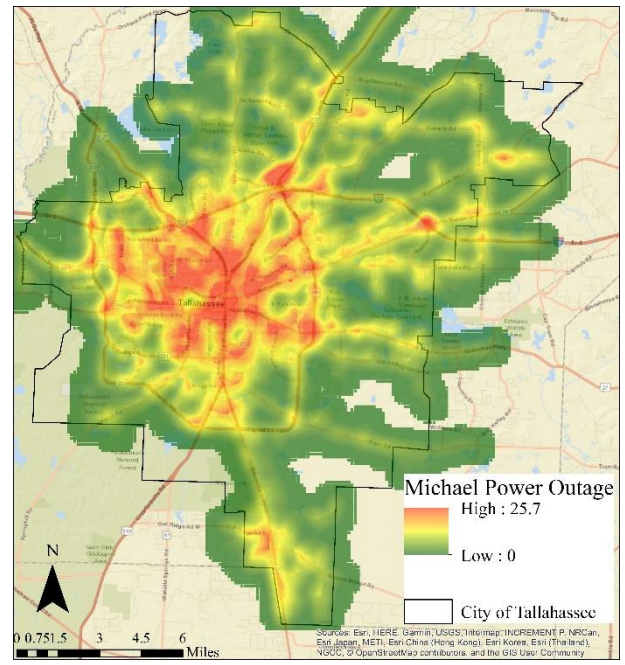

(b)

Figure 5. Cont. 


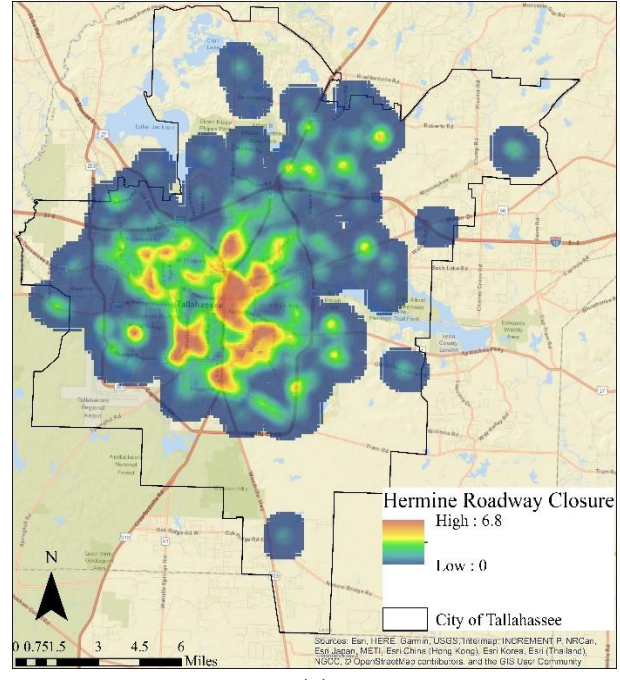

(c)

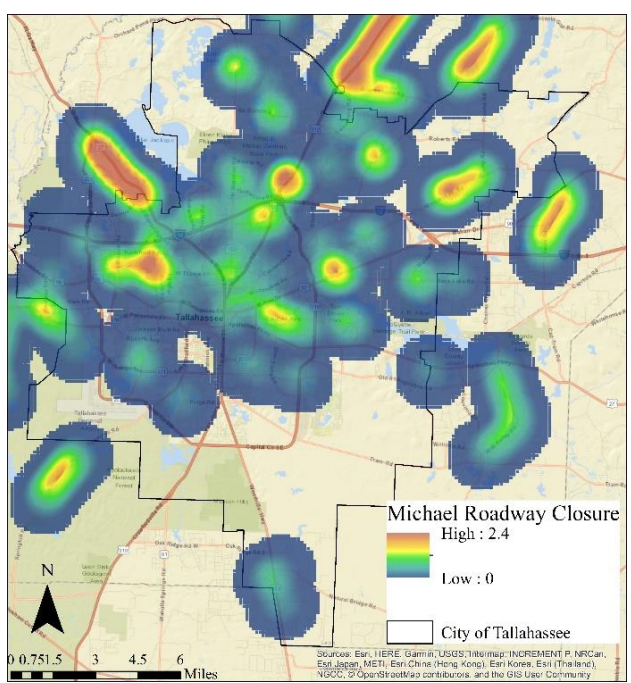

(d)

Figure 5. Power outages cause by Hermine (bandwidth: 200 meters) (a); power outages cause by Michael (b); roadway closures cause by Hermine (c); roadway closures caused by Michael (d). Note that areas in red show higher risk locations for power outages and roadway closures during both hurricanes.

3.1.2. Power Outage and Roadway Closure Density Ratio Differences (DRDs) between Hurricane Hermine and Michael

In order to understand how the impacts of Hermine and Michael were different for the city and to assess the differences in the areas affected by roadway closures and power outages, DRD metric values were obtained for both closures and outages. Figure 6a displays the power outage density ratio differences between Hurricane Michael and Hermine in Tallahassee. The higher value of difference, the higher number of power outages caused by Hurricane Michael in those regions. Based on the findings, it can be concluded that the areas around the city center were impacted by both hurricanes, and there were not many differences. However, it seems Hurricane Michael had a more significant impact on the city, since the difference in the values is higher towards the positive values. However, there were some other regions in the east, northeast, and northwest of Tallahassee that experienced more power outages because of Hurricane Michael which is shown by the purple color.

Similarly, Figure $6 \mathrm{~b}$ shows the roadway closure density ratio difference between hurricanes Michael and Hermine in the city. Similar to Figure 6a, the areas with the higher value of difference reveals that those areas were affected more by Michael in terms of roadway closures, and vice versa. We observe that Hurricane Michael caused more roadway closures around the city border and especially in northeast and northwest Tallahassee (shown clearly with the red color). As discussed before, two major corridors were completely closed during Hurricane Michael, and they affected those areas adversely. In contrast to Michael, Hermine affected the city center drastically and several roadway closures occurred in these regions. This indicated that every hurricane has unique characteristics and the city infrastructure should still be resilient enough to serve those people in the affected areas. This can possibly be achieved by roadway modification and landscaping. Note that roadway closures happen generally due to the fact of fallen trees or pole as opposed to power outages which can happen both because of fallen trees as well as a failure at the substation which can impact the entire power grid. 


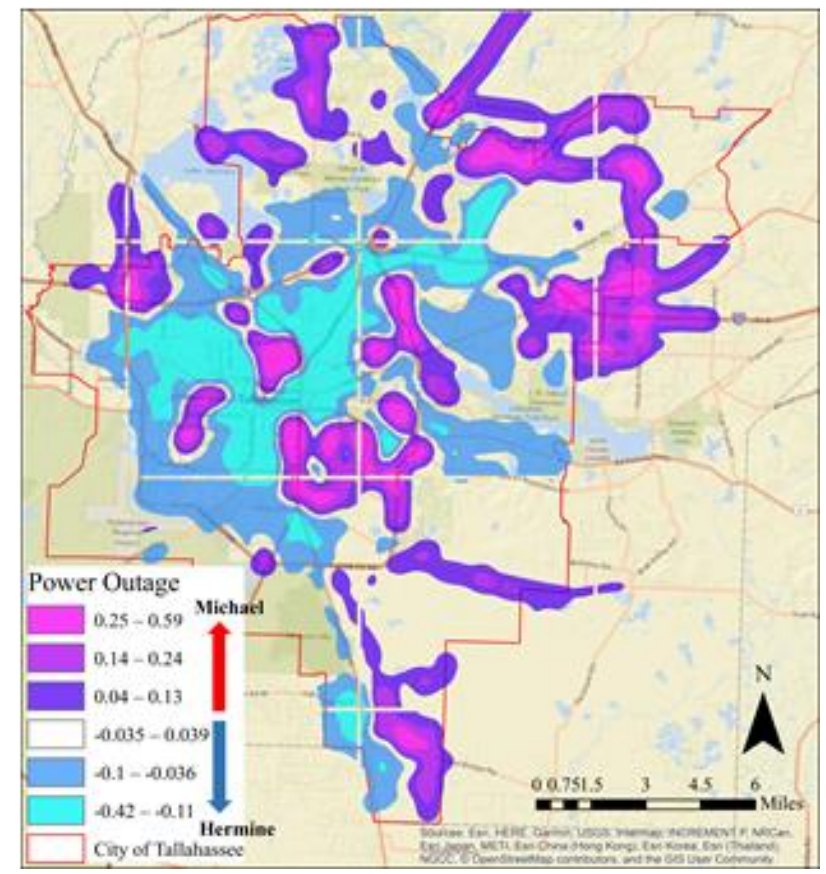

(a)

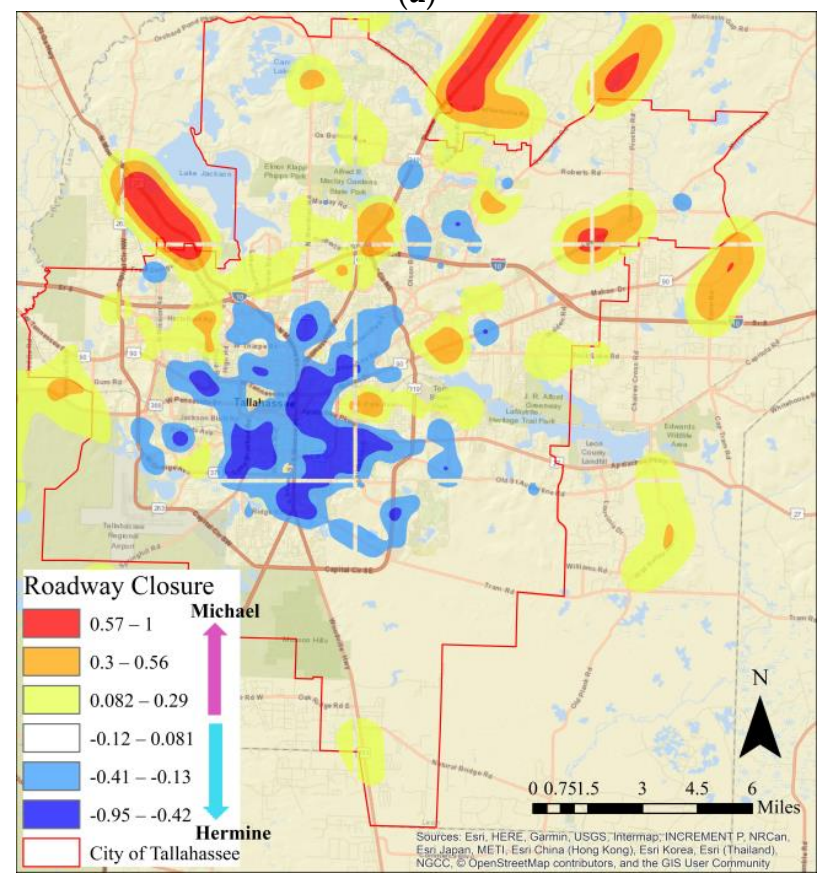

(b)

Figure 6. Density ratio difference between Michael and Hermine: (a) power outages; (b) roadway closures. Note that for power outages, higher densities of power outages caused by Michael are indicated in purple. For those areas with more cyan color, on the other hand, Hermine caused more damages than Michael. Similarly, for the roadways, more red areas indicate those that Michael affected more than Hermine, whereas the opposite is valid for more blue areas.

\subsection{Statistical Analysis Results}

\subsubsection{Hurricane Hermine- and Hurricane Michael-induced Power Outages}

The results of statistical analyses for Hurricane Hermine- and Hurricane Michael-induced power outages are provided in Tables 2 and 3, respectively. In the tables, "Coefficient" values show the positive 
and negative effects of an independent variable on the response variable. "Standard Error" estimates the standard deviation of the coefficients in the model. That is, it measures the precision of the model. Also, " $p$-values" reveal the significance level of different variables on the response variable. In this study, we considered three different significance level including 90\%, 95\%, and 99\%. For each variable, the level of significance has been determined based on the corresponding p-value. Based on the results, five variables seem to have statistically significant effects on power outages induced by Hurricane Hermine at the significance level of $90 \%$ (Table 2). Similarly, five variables are statistically significant with respect to power outages in Hurricane Michael (Table 3). "Land Area $\left(\mathrm{km}^{2}\right)^{\prime \prime}$ variable is not statistically significant even though it has a negative coefficient for Hurricane Hermine-induced power outages. However, this variable has significant effects on power outages due to Hurricane Michael. This indicates that people living in a census block group with larger land areas were affected more by power outages caused by Hurricane Michael. "Average Household Size" variable has a large negative coefficient for both hurricanes. That is, census block groups with larger families experienced less power outages in both hurricanes. Another interesting finding is that "College Degree (\%)" with its negative coefficient is statistically significant for Hurricane Hermine. That is, census block groups where more educated people are living suffered power outages less than the other regions in Hurricane Hermine. One explanation for this finding might be the fact that these residents usually have higher income and live in the areas of the city with more developed infrastructure systems. Moreover, "Transportation Mode: Walk (\%)" parameter reveals that census block groups with higher percentage of people who walk for travel purposes suffered power outages less in Hermine in comparison to the people who use other modes of transportation.

"African American (\%)" variable, on the other hand, shows a different pattern with regards to its positive coefficient in Michael. This means that, census block groups where higher number of African American populations are living suffered roadway closures more than other locations. Also, "Total Length of Underground Power Lines" and "Total Length of Overhead Power Lines" variables are statistically significant with respect to their positive coefficients for power outages. These variables disclose that the longer the power lines, the higher the power outages. As seen in Tables 2 and 3 , positive coefficients of overhead power lines are much larger than underground power lines for both hurricanes. This means that the areas in the city with more overhead lines are more vulnerable to hurricane-induced power outages which is an intuitive finding. As seen in Figure 3a, most of the power lines and more specifically, overhead power lines are distributed around the city center and as stated earlier, the areas around the city center suffered more power outages rather than other regions (Figure 5a,b). Based on the findings for both hurricanes, it can be concluded that power outages are highly associated with the "Total Length of Underground Power Lines" and "Total Length of Overhead Power Lines" variables for both hurricanes Hermine and Michael.

Table 2. Model results for Hurricane Hermine-induced power outages.

\begin{tabular}{|c|c|c|c|c|c|c|}
\hline \multicolumn{7}{|c|}{ Multiple Linear Regression Model: $y \sim 1+x 1+x 2+x 3+x 4+x 5+x 6$} \\
\hline \multicolumn{7}{|c|}{ Estimated Coefficients: } \\
\hline \multirow{2}{*}{ Variables } & \multirow{2}{*}{ Coefficient } & \multirow{2}{*}{ Standard Error } & \multirow{2}{*}{$p$-Value } & \multicolumn{3}{|c|}{ Significance Level } \\
\hline & & & & $99 \%$ & $95 \%$ & $90 \%$ \\
\hline (Intercept) & 188.076 & 53.001 & 0.001 & $\sqrt{ }$ & $\sqrt{ }$ & $\sqrt{ }$ \\
\hline Land Area $\left(\mathrm{km}^{2}\right)$ & -0.460 & 0.320 & 0.153 & $x$ & $\mathrm{x}$ & $\mathrm{x}$ \\
\hline Average Household Size & -54.118 & 15.503 & 0.001 & $\sqrt{ }$ & $\sqrt{ }$ & $\sqrt{ }$ \\
\hline College Degree (\%) & -0.888 & 0.416 & 0.035 & $x$ & $\sqrt{ }$ & $\sqrt{ }$ \\
\hline Transportation Mode: Walk (\%) & -2.394 & 1.338 & 0.076 & $\mathrm{x}$ & $x$ & $\sqrt{ }$ \\
\hline$\sum$ Length of UG Power Lines (m) & 9.465 & 2.278 & 0.000 & $\sqrt{ }$ & $\sqrt{ }$ & $\sqrt{ }$ \\
\hline $\bar{\Sigma}$ Length of $\mathrm{OH}$ Power Lines (m) & 39.383 & 3.811 & 0.000 & $\sqrt{ }$ & $\sqrt{ }$ & $\sqrt{ }$ \\
\hline
\end{tabular}

Note: 157 observations, 150 error degrees of freedom, Multiple R-squared: 0.4695, Adjusted R-squared: 0.4483. Residual standard error: 71.59 , F-statistic: $22.12, p$-value $\approx 0$. 
Table 3. Model results for Hurricane Michael-induced power outages.

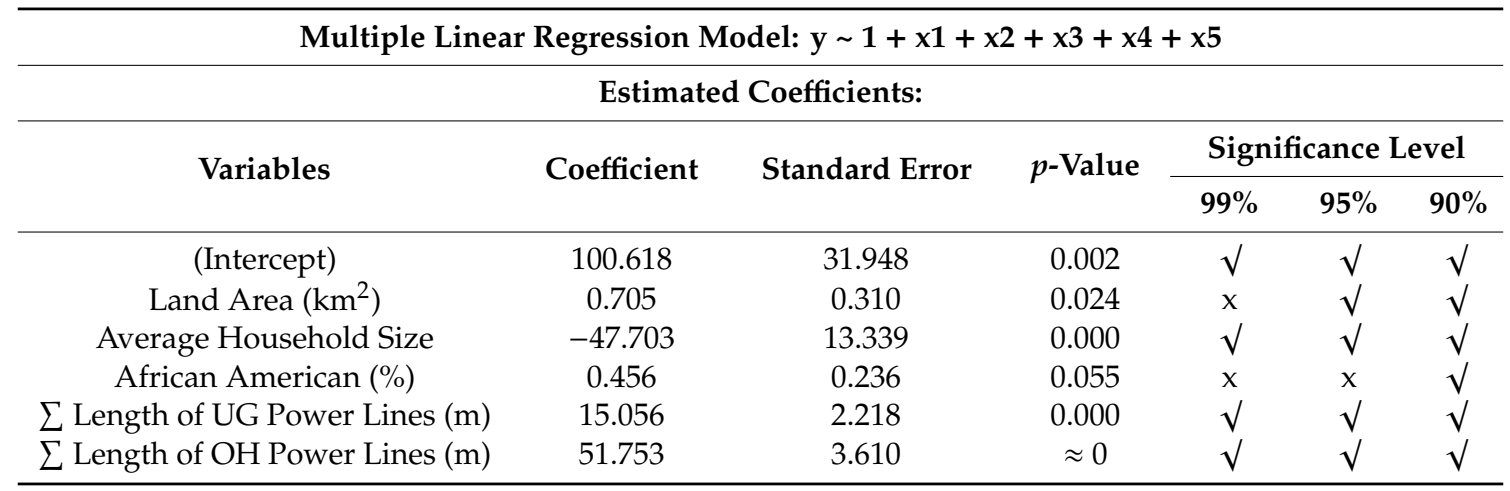

Note: 157 observations, 151 error degrees of freedom, Multiple $R$-squared: 0.6626, Adjusted $R$-squared: 0.6514.

Residual standard error: 69.12 , F-statistic: $59.31, p$-value: $\approx 0$.

\subsubsection{Hurricane Hermine- and Hurricane Michael-induced Roadway Closures}

The results of the statistical models for Hurricane Hermine and Michael induced roadway closures are summarized in Tables 4 and 5. According to the obtained results, five variables are statistically significant regarding the Hurricane Hermine-induced roadway closures in the city (Table 4). Also, five variables have significant effects on roadway closures caused by Hurricane Michael (Table 5). Similar to Hurricane Hermine-induced power outages, the same assessment holds for "Land Area $\left(\mathrm{km}^{2}\right)^{\prime \prime}$ and "Average Household Size" variables for Hermine-induced roadway closures. Additionally, "African American (\%)" parameter indicates that census block groups with higher percentage of African American populations were affected more by roadway closures in Hermine. "Young (18-21) $(\%)^{\prime \prime}$ variable reveals a different pattern due to its negative coefficient in the case of Hurricane Michael. That is, census block groups where higher percentage of young (18-21) population are living suffered roadway closures less in Michael. According to Figures $3 e$ and $5 d$, this result was expected. Also, "Total Length of Overhead Power Lines" variable had statistically significant impacts on roadway closures induced by both hurricanes. This indicates that the longer the power lines, the higher the roadway closures. Similarly, "Total Length of Underground Power Lines" was statistically significant at a significance level of $90 \%$ for roadway closures caused by Michael. However, the findings reveal that "Total Length of Underground Power Lines" was not statistically significant for the case of Hurricane Hermine. A comparison between Figures $3 \mathrm{a}$ and $5 \mathrm{c}$ discloses that most of the overhead power lines are clustered in the areas of the city where more roadway closures were reported in Hurricane Hermine. Another interesting finding is that "Emergency Facility Area" with its positive coefficient was statistically significant in Hurricane Hermine. That is, census block groups closer to critical facilities experienced roadway closures more than other areas. As seen in Figure $3 c$, most of these facilities are distributed around the city center and the areas around the city center (where critical facilities are located generally) suffered more roadway closures rather than other regions in the case of Hermine (Figure 5c). "Built After 2014 (\%)" shows that census block groups with higher percentage of housing units built 2014 or later suffered more roadway closures caused by Michael. "Disability (\%)" variable, on the other hand, shows a different pattern due to its negative coefficient. That is, census block groups with a higher percentage of people (20-64 Years) with a disability were less affected by the roadway closures due to Michael. 
Table 4. Model results for Hurricane Hermine-induced roadway closures.

\begin{tabular}{|c|c|c|c|c|c|c|}
\hline \multicolumn{7}{|c|}{ Multiple Linear Regression Model: $y \sim 1+x 1+x 2+x 3+x 4+x 5$} \\
\hline \multicolumn{7}{|c|}{ Estimated Coefficients: } \\
\hline \multirow{2}{*}{ Variables } & \multirow{2}{*}{ Coefficient } & \multirow{2}{*}{ Standard Error } & \multirow{2}{*}{$p$-Value } & \multicolumn{3}{|c|}{ Significance Level } \\
\hline & & & & $99 \%$ & $95 \%$ & $90 \%$ \\
\hline (Intercept) & 33.052 & 7.411 & 0.000 & $\sqrt{ }$ & $\sqrt{ }$ & $\sqrt{ }$ \\
\hline Land Area $\left(\mathrm{km}^{2}\right)$ & -0.166 & 0.071 & 0.021 & $x$ & $\sqrt{ }$ & $\sqrt{ }$ \\
\hline Average Household Size & -11.738 & 3.035 & 0.000 & $\sqrt{ }$ & $\sqrt{ }$ & $\sqrt{ }$ \\
\hline African American (\%) & 0.119 & 0.051 & 0.021 & $x$ & $\sqrt{ }$ & $\sqrt{ }$ \\
\hline$\sum$ Length of $\mathrm{OH}$ Power Lines (m) & 2.442 & 0.831 & 0.004 & $\sqrt{ }$ & $\sqrt{ }$ & $\sqrt{ }$ \\
\hline Emergency Facility Area & 0.163 & 0.073 & 0.027 & $x$ & $\sqrt{ }$ & $\sqrt{ }$ \\
\hline
\end{tabular}

Note: 157 observations, 151 error degrees of freedom, Multiple R-squared: 0.212, Adjusted $R$-squared: 0.1859. Residual standard error: 15.8, F-statistic: $8.123, p$-value: $\approx 0$.

Table 5. Model results for Hurricane Michael-induced roadway closures.

\begin{tabular}{|c|c|c|c|c|c|c|}
\hline \multicolumn{7}{|c|}{ Multiple Linear Regression Model: $y \sim 1+x 1+x 2+x 3+x 4+x 5$} \\
\hline \multicolumn{7}{|c|}{ Estimated Coefficients: } \\
\hline \multirow{2}{*}{ Variables } & \multirow{2}{*}{ Coefficient } & \multirow{2}{*}{ Standard Error } & \multirow{2}{*}{$p$-Value } & \multicolumn{3}{|c|}{ Significance Level } \\
\hline & & & & $99 \%$ & $95 \%$ & $90 \%$ \\
\hline (Intercept) & 4.429 & 1.773 & 0.014 & $\mathrm{x}$ & $\sqrt{ }$ & $\sqrt{ }$ \\
\hline Young (18-21) (\%) & -0.092 & 0.035 & 0.008 & $\sqrt{ }$ & $\sqrt{ }$ & $\sqrt{ }$ \\
\hline Built After $2014(\%)$ & 0.871 & 0.335 & 0.010 & $x$ & $\sqrt{ }$ & $\sqrt{ }$ \\
\hline Disability $(\%)$ & -0.167 & 0.073 & 0.024 & $x$ & $\sqrt{ }$ & $\sqrt{ }$ \\
\hline$\sum$ Length of UG Power Lines (m) & 0.449 & 0.185 & 0.016 & $x$ & $\sqrt{ }$ & $\sqrt{ }$ \\
\hline $\bar{\Sigma}$ Length of $\mathrm{OH}$ Power Lines (m) & 0.995 & 0.314 & 0.002 & $\sqrt{ }$ & $\sqrt{ }$ & $\sqrt{ }$ \\
\hline
\end{tabular}

Mote: 157 observations, 151 error degrees of freedom, Multiple R-squared: 0.219, Adjusted R-squared: 0.1931.

Residual standard error: 5.982, F-statistic: $8.468, p$-value: $\approx 0$.

\subsection{Final Discussion of the Results}

The spatial model results indicated that the high-risk locations for roadway closures showed different patterns for the two hurricanes. Roadways around the downtown suffered substantially during Hermine, whereas roadway closures did not show specific clusters for Michael. On the other hand, power outages seem to have similar spatial patterns for both hurricanes with the significant impacts on residents living around the city center. However, the spatial results obtained may not guarantee that the high-risk locations found possess statistical significance. In addition, the visual results do not provide any information on which population segment has been impacted more than others. A regression analysis, on the other hand, enabled us to interpret which communities were impacted more by the hurricanes in the city via the introduction of demographics- and socioeconomics-related variables in the regression model.

The information gained by statistical models showed that census block groups where higher percentage of educated people were living suffered power outages less in Hurricane Hermine. The results also revealed that there were more power outages where the length of power lines was larger, and census block groups with overhead power lines were more vulnerable to power outages in both hurricanes. On the other hand, census block groups with larger families experienced less power outages than other areas. In terms of roadway closures, the results revealed that African American population suffered more roadway closures in Hermine. Similar to power outages in both hurricanes, longer overhead power lines were associated with increasing roadway closures. Also, census block groups where young (18-21) populations were living were less affected by roadway closures caused by Hurricane Michael. 
The findings of this study reveal the critical locations of the city that are under risk of disruption due to the fact of hurricanes which can enable emergency and city officials to make accurate estimations and identify the most vulnerable areas with a specific focus on roadway closures and power outages in order to alleviate future disruptions. This might be obtained by deploying the restoration equipment and personnel closer to these areas or establishing new emergency response facilities.

As a possible impact on developing urban development policies, the findings of this study can help delineate the areas and the residents in the city that are under high risk of disruptions caused by hurricanes. This type of analysis can help planners and emergency officials develop better strategies in identifying critical and less resilient regions and make accurate estimations for targeted locations. This information can be utilized to improve emergency response and urban development plans by identifying and building the optimal roadway infrastructure which can help provide alternative emergency routes to public in the case of a hurricane.

\section{Conclusions and Future Work}

In this study, the impacts of Hurricane Hermine (2016) and Hurricane Michael (2018) on the City of Tallahassee were assessed using GIS-based spatial and statistical analyses. Spatial analysis was conducted via a series of spatial analytic methods to explore the power outages and roadway closures patterns including the KDE and the DRD methods. The latter was specifically utilized in order to understand how the impacts of Hermine and Michael were different for the city and to assess the differences in locations where power failures and roadway closures were experienced. Statistical analysis, on the other hand, was performed to provide critical information about the relationship between the magnitude of power outages and roadway closures induced by these hurricanes and different socioeconomics-, demographics-, and transportation-related variables.

The results of this analysis indicate the following: (a) density ratio approach clearly indicates that outage and closure maps for the hurricanes have different geo-spatial patterns, (b) a substantial amount of power outages and roadway closures happened around the center of Tallahassee, and (c) vulnerable population segments based on income and ethnicity suffered more from outages and closures. These are important findings which basically separates those population groups from others. This knowledge can allow planners and engineers to focus on those high-risk areas for safety-focused intervention efforts to assist populations in need of power and accessibility. This can also help increasing the efficiency of the emergency operations towards obtaining better policies and plans that focus on populations at risk.

As a future work, the effects of downed trees on the transportation and power networks can be considered. Also, studying the problem temporally and looking at different temporal patterns of solving the power outage and roadway closure problems is a good direction of future research to consider. Furthermore, this study could be extended to using other methods such as Bayesian models to predict the power outages and roadway closures based on different predictors. Also, using particle filtering or Kalman filtering (linear quadratic estimation), the information related to hurricane's track can be added to the model [43-45].

There are several limitations to this study. For instance, as stated in the "Study Area and Data Description", the roadway closures and power outages data were obtained via DigiTally mobile app in which the city residents can report the outages or closures online. Hence, there is a possibility that some closures or outages in the city were not reported by the residents and this can indicate some missing closure and outage data. Moreover, hurricane path as well as wind speed and direction are other variables that can affect power outages and roadway closures and have not been considered in this paper due to data availability. This is especially critical to have a more accurate measure of the hurricane's impact on roadway and power grid. As a future study, the impact of hurricane track, wind speed, and direction on power outages and roadway closures will be investigated when the data are available. In addition, to further understand the actual impact of the hurricane, high-risk locations should be studied in more detail. 
Author Contributions: The authors confirm contributions to the paper as follows: study conception and design, M.G., M.K., E.E.O., M.B.U.; analysis and interpretation of results, M.G., E.E.O. and M.B.U.; manuscript preparation, M.G., M.K., E.E.O., M.B.U. and R.A. All authors reviewed the results and approved the final version of the manuscript.

Funding: This project was partially sponsored by the US NSF award 1832068.

Acknowledgments: The authors would like to thank the Florida Department of Transportation and the City of Tallahassee for providing the data. The contents of this paper and discussion represent the authors' opinions and do not reflect the official view of the National Science Foundation, Florida Department of Transportation, and the City of Tallahassee.

Conflicts of Interest: The authors declared no potential conflicts of interest with respect to research, authorship, and/or publication of this article.

\section{References}

1. Tabs Beven, J.L.; Berg, R.; Hagen, A. Hurricane Michael. In Tropical Cyclone Report; AL142018; National Hurricane Center, 2019; 86p. Available online: https://www.nhc.noaa.gov/data/tcr/AL142018_Michael.pdf (accessed on 20 December 2019).

2. FEMA, Federal Emergency Management Agency, United States Department of Homeland. Available online: https://www.fema.gov/ (accessed on 25 December 2018).

3. Centre for Research on the Epidemiology of Disasters. Natural Disasters 2017: Lower Mortality, Higher Cost; Centre for Research on the Epidemiology of Disasters: Brussels, Belgium, 2018; p. 8.

4. National Weather Service. Catastrophic Hurricane Michael Strikes Florida Panhandle October 10. 2018. Available online: https://www.weather.gov/tae/HurricaneMichael2018 (accessed on 10 October 2019).

5. Ulak, M.B.; Kocatepe, A.; Konila Sriram, L.M.; Ozguven, E.E.; Arghandeh, R. Assessment of the hurricaneinduced power outages from a demographic, socioeconomic, and transportation perspective. Nat. Hazards 2018, 92, 1489-1508. [CrossRef]

6. Xian, S.; Feng, K.; Lin, N.; Marsooli, R.; Chavas, D.; Chen, J.; Hatzikyriakou, A. Rapid Assessment of Damaged Homes in the Florida Keys after Hurricane Irma. Nat. Hazards Earth Syst. Sci. Discuss. 2018, 2041-2045. [CrossRef]

7. Botts, H.; Du, W.; Jeffery, T.; Kolk, S.; Pennycook, Z.; Suhr, L. 2015 CoreLogic@Storm Surge Report; CoreLogic: Irvine, CA, USA, 2015; p. 44.

8. Faturechi, R.; Miller-Hooks, E. Travel time resilience of roadway networks under disaster. Transp. Res. Part B Methodol. 2014, 70, 47-64. [CrossRef]

9. Larsen, T.; Porter, K.; Zadeh, M.; Van Anne, C.; Scawthorn, C. Impact of Hurricane Andrew on Performance Interaction and Recovery of Lifelines. Final Rep. Natl. Sci. Found. 1996.

10. Linask, E. Hurricane Michael Leaves Nearly All of Tallahassee without Power. Available online: https://www. powerprotectionresource.com/articles/439879-hurricane-michael-leaves-nearly-all-tallahassee-without-power.htm (accessed on 10 October 2019).

11. Morris, K.; Johnson, A. Workshop on the Hurricane Hermine After Action Report; NOAA: Silver Spring, MD, USA, 2016.

12. Pinzan, D.; Kocatepe, A.; Gilanifar, M.; Ulak, M.B.; Ozguven, E.E.; Arghandeh, R. Data-Driven and Hurricane-Focused Metrics for Combined Transportation and Power Networks Resilience. In Proceedings of the Transportation Research Board 97th Annual Meeting, 18-0574, Transportation Research Board, Washington, DC, USA, 7-11 January 2018.

13. Kocatepe, A.; Ulak, M.B.; Sriram, L.M.K.; Pinzan, D.; Ozguven, E.E.; Arghandeh, R. Co-resilience Assessment of Hurricane-induced Power Grid and Roadway Network Disruptions: A Case Study in Florida with a Focus on Critical Facilities. In Proceedings of the 2018 21st International Conference on Intelligent Transportation Systems (ITSC), Maui, HI, USA, 4-7 November 2018; pp. 2759-2764.

14. Chang, S.E. Infrastructure Resilience to Disasters. In Proceedings of the 2009 Frontiers of Engineering Symposium, Session on Resilient and Sustainable Infrastructures, Frontiers of Engineering, Irvine, CA, USA, 10-12 September 2009; p. 4.

15. Mitsova, D.; Escaleras, M.; Sapat, A.; Esnard, A.M.; Lamadrid, A.J. The effects of infrastructure service disruptions and socio-economic vulnerability on Hurricane recovery. Sustainability 2019, 11, 516. [CrossRef] 
16. Sriram, L.M.K.; Ulak, M.B.; Ozguven, E.E.; Arghandeh, R. Multi-Network Vulnerability Causal Model for Infrastructure Co-Resilience. Inst. Electr. Electron. Eng. (IEEE) Access 2019, 7, 35344-35358.

17. Yuan, F.; Liu, R. Feasibility study of using crowdsourcing to identify critical affected areas for rapid damage assessment: Hurricane Matthew case study. Int. J. Disaster Risk Reduct. 2018, 28, 758-767. [CrossRef]

18. Ullman, D.S.; Ginis, I.; Huang, W.; Nowakowski, C.; Chen, X.; Stempel, P. Assessing the multiple impacts of extreme hurricanes in southern new England, USA. Geoscience 2019, 9, 265. [CrossRef]

19. Rey, W.; Salles, P.; Torres-Freyermuth, A.; Ruiz-Salcines, P.; Teng, Y.C.; Appendini, C.M.; Quintero-Ibanez, J. Spatiotemporal Storm Impact on the Northern Yucatan Coast during Hurricanes and Central American Cold Surge Events. J. Mar. Sci. Eng. 2019, 8, 2. [CrossRef]

20. Davidson, R.A.; Liu, H.; Sarpong, K.; Sparks, P.; Rosowsky, D.V. Electric power distribution system performance in Carolina Hurricanes. Nat. Hazards Rev. 2003, 4, 36-45. [CrossRef]

21. Demiroluk, S.; Ozbay, K. Bayesian Spatial Modeling and Risk Mapping of Downed Trees along the Roadways Using Data from Hurricanes Irene and Sandy. In Proceedings of the Transportation Research Board 94th Annual Meeting, Washington, DC, USA, 11-15 January 2015; pp. 1-23.

22. Li, H.; Treinish, L.A.; Hosking, J.R.M. A statistical model for risk management of electric outage forecasts. IBM J. Res. Dev. 2010, 54, 1-8. [CrossRef]

23. Liu, H.; Davidson, R.A.; Apanasovich, T.V. Spatial generalized linear mixed models of electric power outages due to hurricanes and ice storms. Reliab. Eng. Syst. Saf. 2008, 93, 897-912. [CrossRef]

24. Reed, D.A. Electric utility distribution analysis for extreme winds. J. Wind Eng. Ind. Aerodyn. 2008, 96, 123-140. [CrossRef]

25. Liu, H.; Davidson, R.A.; Rosowsky, D.V.; Stedinger, J.R. Negative binomial regression of electric power outages in hurricanes. J. Infrastruct. Syst. 2005, 11, 258-267. [CrossRef]

26. Eskandarpour, R.; Khodaei, A. Machine Learning Based Power Grid Outage Prediction in Response to Extreme Events. IEEE Trans. Power Syst. 2017, 32, 3315-3316. [CrossRef]

27. Han, S.R.; Guikema, S.D.; Quiring, S.M. Improving the predictive accuracy of hurricane power outage forecasts using generalized additive models. Risk Anal. 2009, 29, 1443-1453. [CrossRef]

28. Guikema, S.D.; Nateghi, R.; Quiring, S.M.; Staid, A.; Reilly, A.C.; Gao, M. Predicting Hurricane Power Outages to Support Storm Response Planning. IEEE Access 2014, 2, 1364-1373. [CrossRef]

29. Kocatepe, A.; Ulak, M.B.; Kakareko, G.; Ozguven, E.E.; Jung, S.; Arghandeh, R. Measuring the accessibility of critical facilities in the presence of hurricane-related roadway closures and an approach for predicting future roadway disruptions. Nat. Hazards 2019, 95, 615-635. [CrossRef]

30. Sultan, V.; Hilton, B. A spatial analytics framework to investigate electric power-failure events and their causes. ISPRS Int. J. Geo-Inf. 2020, 9, 54. [CrossRef]

31. US Census, Population and Housing Unit Estimates. 2017. Available online: https://www.fgdl.org/ metadataexplorer/explorer.jsp (accessed on 20 October 2019).

32. Berg, R. Hurricane Hermine. New Sci. 2016, 231, 4-5.

33. Cangialosi, J.P.; Latto, A.S.; Berg, R. National Hurricane Center Tropical Cyclone Report-Hurricane Irma (AL112017) 30 August-12 September 2017; National Oceanic and Atmospheric Administration: Washington, DC, USA, 2018; p. 111.

34. AccuWeather 2017. Available online: https://www.accuweather.com/en/us/tallahassee-fl/weather-radar. (accessed on 10 October 2019).

35. Hurricane Hermine. National Weather Service. 2017. Available online: https://radar.weather.gov/radar.php? rid=tlh (accessed on 10 October 2019).

36. Hurricane Michael. National Weather Service. 2019. Available online: https://www.weather.gov/mob/michael (accessed on 15 November 2019).

37. DigiTally. Available online: https://www.talgov.com/Main/digitally.aspx (accessed on 15 November 2019).

38. Florida Geographic Data Library. Available online: https://www.fgdl.org/metadataexplorer/explorer.jsp (accessed on 15 January 2019).

39. Xie, Z.; Yan, Y. Detecting traffic accident clusters with network kernel density estimation and local spatial statistics: An integrated approach. J. Transp. Geogr. 2013, 31, 64-71. [CrossRef]

40. Ulak, M.B.; Ozguven, E.E.; Spainhour, L.; Vanli, O.A. Spatial investigation of aging-involved crashes: A GIS-based case study in Northwest Florida. J. Transp. Geogr. 2017, 58, 71-91. [CrossRef] 
41. Blazquez, C.A.; Celis, M.S. A spatial and temporal analysis of child pedestrian crashes in Santiago, Chile. Accid. Anal. Prev. 2013, 50, 304-311. [CrossRef] [PubMed]

42. Xie, Z.; Yan, J. Kernel Density Estimation of traffic accidents in a network space. Comput. Environ. Urban Syst. 2008, 32, 396-406. [CrossRef]

43. Mutaf, A. A Kalman filter with smoothing for hurricane tracking and prediction. Master's Thesis, Naval Postgraduate School, Monterey, CA, USA, December 1989.

44. Martino, L.; Read, J.; Elvira, V.; Louzada, F. Cooperative parallel particle filters for online model selection and applications to urban mobility. Digit. Signal Process. A Rev. J. 2017, 60, 172-185. [CrossRef]

45. Svendsen, D.H.; Martino, L.; Camps-Valls, G. Active emulation of computer codes with Gaussian processes-Application to remote sensing. Pattern Recognit. 2020, 100, 107103. [CrossRef]

(C) 2020 by the authors. Licensee MDPI, Basel, Switzerland. This article is an open access article distributed under the terms and conditions of the Creative Commons Attribution (CC BY) license (http://creativecommons.org/licenses/by/4.0/). 